\title{
Response of plasma pancreatic and gastrointestinal hormones and growth hormone to oral and intravenous glucose and insulin hypoglycaemia in Chagas's disease
}

\author{
R G LONG*, R H ALBUQUERQUE, A PRATA, A J BARNES, T E ADRIAN, \\ N D CHRISTOFIDES, AND S R BLOOM
}

From the Departments of Medicine, Hammersmith Hospital, Royal Postgraduate Medical School, London, and University' of Brasilia, Brasil

SUMMARY Plasma hormonal responses to insulin hypoglycaemia and to oral and intravenous glucose were investigated in chagasic patients with severe bowel disease and compared with controls matched for age, sex, weight, and race. After intravenous insulin, plasma concentrations of pancreatic glucagon and pancreatic polypeptide (PP) were reduced in the patients with Chagas's disease. These subjects also showed a subnormal rise in plasma insulin after oral glucose. Other hormone responses did not differ significantly from those in the normal controls. These results are compatible with partial denervation of the pancreatic alpha, beta, and PP cells in patients with chronic gastrointestinal Chagas's disease.

Chagas's disease is caused by the flagellate protozoon Trypanosoma cruzi, is usually acquired by South Americans after a bite from an infected reduviid bug, and affects some 10 million people. An acute illness, sometimes with severe myocarditis and meningoencephalitis, may follow but the majority of infected patients recover and enter the latent phase. The asymptomatic period of chronic infection lasts for many years but some patients subsequently develop evidence of cardiac and gastrointestinal complications. The gastrointestinal form of chronic Chagas's disease is characterised most commonly by clinical megaoesophagus and megacolon due to destruction of nerves and ganglion cells in Meissner's and Auerbach's pluxuses. ${ }^{1-3}$ Pancreatic endocrine and exocrine function has not been tested in this disease and studies on pancreatic innervation have not been performed.

Studies on the calf and other animals, using pharmacological blocking agents and nerve section, have shown the importance of the vagus in the release of pancreatic glucagon and pancreatic polypeptide. During insulin hypoglycaemia or after

*Present address: Department of Gastroenterology, St. Thomas' Hospital, London SE1 7EH.

Received for publication 14 April 1980 2-deoxy glucose administration, for example, vagotomised calves show defective islet cell function. ${ }^{45}$ In man truncal vagotomy appears to cause attenuation of the plasma pancreatic glucagon response to insulin hypoglycaemia. ${ }^{6}$ There is also much evidence in man that pancreatic polypeptide secretion is under cholinergic control. ${ }^{7}$ We have therefore studied the humoral response of the pancreas and gut to oral and intravenous glucose and insulin in patients with chronic gastrointestinal Chagas's disease to assess the presence and effect of denervation of pancreatic endocrine cells.

\section{Methods}

Clinical details of the 14 Brasilian patients studied are shown in Table 1 . The mean age $( \pm$ SEM $)$ of the chagasic patients was $46 \pm 5$ and of the controls $37 \pm 6$. Seven of the chagasic patients had a history of dysphagia (cases 2,3 , and 4 had had oesophageal surgery) and five had severe constipation (cases 2 and 4 had had colonic surgery). Barium studies showed evidence of gross (grade III-IV) megaosophagus $^{2}$ in seven chagasic patients and five also had megacolon. Each of the patients gave informed verbal consent. In patients with oesophageal stasisfor example, patient 6-the oral glucose tolerance 
Table 1 Clinical details of patients studied

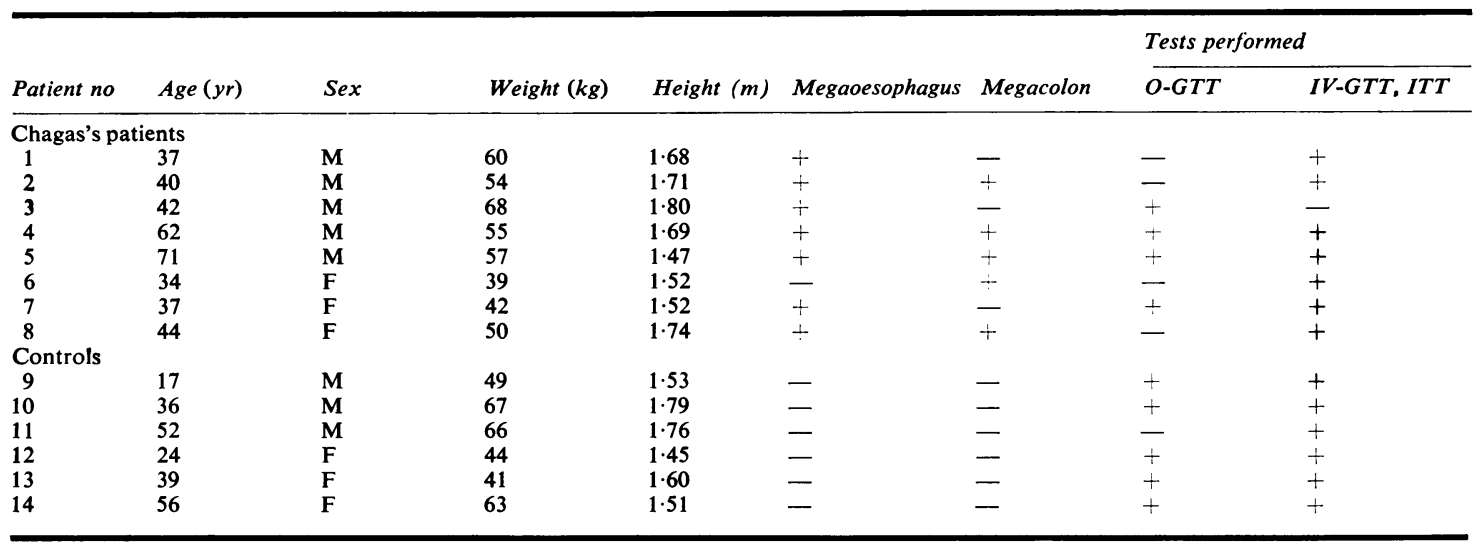

(O-GTT: oral glucose tolerance test; IV-GTT, ITT: intravenous glucose and insulin test).

test was not performed. Four of the chagasic patients and five of the controls had the oral glucose tolerance test and six chagasic patients and seven controls had the intravenous glucose and insulin tests.

The diagnosis of Chagas's disease was confirmed in all the patients by positive serological tests using the immunofluorescent test and complement fixation test of Machado and Guerreiro. ${ }^{8}$ Xenodiagnosis to test the presence of the parasite in the peripheral blood was also performed, ${ }^{9}$ and was positive in the majority of patients. All the patients with Chagas's disease originated from endemic areas. None of the patients complained of symptoms suggestive of marked cardiac disease but electrocardiography showed complete heart block in patient 1 , first degree atrioventricular block with occasional unifocal ventricular ectopics in patient 2 , and left bundle branch block in patient 7 . Sialorrhoea was a feature in patients $1,2,5$, and 8 . In contrast, the controls had negative serological tests for Chagas's disease and came from adjacent areas where Chagas's disease was not endemic.

All subjects were investigated after a 12 hour overnight fast and venous blood samples were drawn from the antecubital fossa through a cannula kept patent with heparinised saline. In the oral glucose tolerance tests blood was taken at -10 , zero, $30,60,90,120$, and 180 minutes after $100 \mathrm{~g}$ glucose dissolved in $400 \mathrm{ml}$ water. Intravenous glucose tolerance tests and insulin hypoglycaemia were carried out consecutively on a subsequent day. Blood was taken at -10 , zero, 3, 5, 10, 20,30, 60, and 90 minutes after a bolus of $50 \%$ D-glucose $(0 \cdot 15 \mathrm{~g}$ dextrose $/ \mathbf{k g}$ body weight). Intravenous soluble insulin $(0.15 \mathrm{U}$ insulin $/ \mathrm{kg})$ was given at time 90 minutes and additional blood taken at 120, 135,
150,180 , and 210 minutes. Samples were collected into fluoride for the estimation of blood glucose and into heparin with $400 \mathrm{KIU}$ aprotinin (Trasylol) per $\mathrm{ml} /$ blood for assay of plasma hormones. The hormone samples were immediately centrifuged and the plasma decanted and stored at $-20^{\circ} \mathrm{C}$ until radioimmunoassay within two months. Previous studies have shown no change in plasma hormone concentrations for storage periods up to one year.

Plasma concentrations of insulin, ${ }^{10}$ pancreatic polypeptide, ${ }^{11}$ motilin, ${ }^{12}$ growth hormone, ${ }^{13}$ gastrin, ${ }^{14}$ and gastric inhibitory polypeptide ${ }^{15}$ were measured by previously characterised radioimmunoassays. Pancreatic glucagon ${ }^{16-18}$ and enteroglucagon ${ }^{19}$ were also measured by radioimmunoassay using similar separation techniques, assay volumes, and buffer as for the radioimmunoassay of gastric inhibitory polypeptide. Antisera were raised to pancreatic glucagon and pancreatic glucagon (World Health Organisation number 69/194) was used for both standards and label, which was obtained by $\mathrm{I}^{125}$ chloramine-T oxidation..$^{20}$ One antiserum was $\mathrm{N}$-terminal reactive and appeared to react fully with enteroglucagon (glucagon-like immunoreactivity of intestinal origin) giving $100 \%$ cross-reaction with pure glicentin standard (porcine enteroglucagon). The other antiserum reacted only with $\mathrm{C}$ terminal fragments of glucagon and reacted with enteroglucagon to less than $5 \%$ of that seen with the $\mathrm{N}$-terminal antibody. This latter antiserum could detect changes of plasma pancreatic glucagon of $1.5 \mathrm{pmol} / \mathrm{l}$ with $95 \%$ confidence. Plasma enteroglucagon was measured by subtracting pancreatic glucagon from the total glucagon concentration measured by the $\mathrm{N}$-terminally reactive antiserum. Changes of $4 \mathrm{pmol} / 1$ plasma enteroglucagon concentration could be detected with $95 \%$ confidence. 
Table 2 Blood glucose and plasma insulin and pancreatic glucagon (mean $\pm S E M)$ after $100 \mathrm{~g}$ oral D-glucose in controls and patients with Chagas's disease

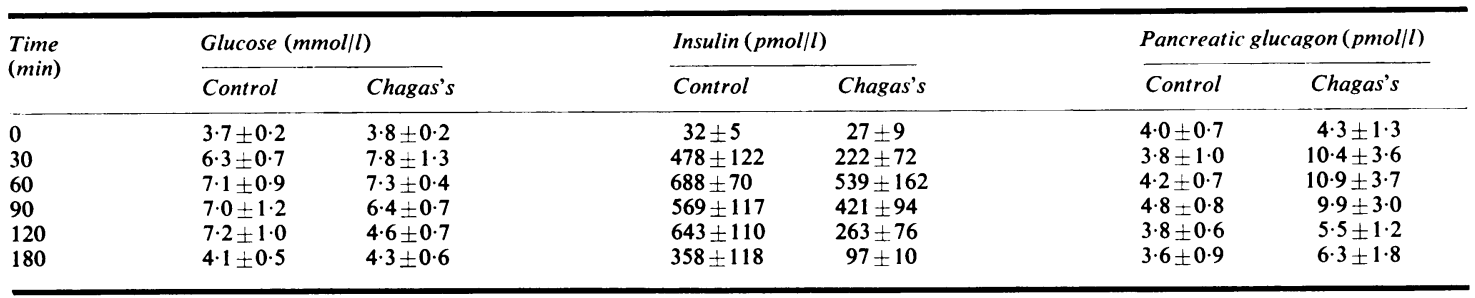

Neither antiserum showed any cross-reactivity with secretin, vasoactive intestinal polpeptide, or gastric inhibitory polypeptide up to concentrations of 100 $\mathrm{nmol} / 1$. Interassay variation was less than $15 \%$ for all radioimmunoassays used.

Statistical analysis was performed by Student's $t$ test for unpaired data, and if there was non-normality, by the Mann-Whitney $U$ test. Results are expressed as means \pm SEM.

\section{Results}

ORAL GLUCOSE TOLERANCE TEST

None of the patients had a diabetic glucose tolerance curve by the criteria of the American Diabetic Association for a $100 \mathrm{~g}$ glucose load. The blood glucose concentrations initially rose higher in the chagasic patients than in the controls, but the insulin response was reduced (Table 2), particularly at 120 minutes $(\mathrm{P}<0.025)$. This reduced insulin response was associated with higher mean blood glucose concentrations in the Chagas's disease patients for the first hour of the test. There was a paradoxical rise in pancreatic glucagon in both groups.

The basal plasma concentrations and response to oral glucose of pancreatic polypeptide, gastric inhibitory polypeptide, motilin, and growth hormone were similar in the chagasic patients and controls. Two chagasic patients had very large plasma enteroglucagon rises but these patients were not unusual in other respects. There was no overall significant difference in enteroglucagon between the controls and patients. The plasma concentrations of pancreatic polypeptide, gastrin, gastric inhibitory polypeptide, and enteroglucagon rose and those of motilin and growth hormone fell after oral glucose. Plasma gastrin concentrations were higher in the chagasic patients but the difference was not significant.

\section{INTRAVENOUS GLU COSE TOLERANCE TEST}

The results of the intravenous glucose tolerance test for blood glucose, insulin, and pancreatic glucagon are shown in Table 3. The plasma insulin responses were similar and there was a normal fall of pancreatic glucagon in both groups.

Plasma pancreatic polypeptide, gastric inhibitory polypeptide, motilin, enteroglucagon, and growth hormone responses were similar. Plasma gastrin, motilin, and growth hormone fell but the other hormone concentrations did not change. All responses had returned to basal after 90 minutes.

\section{INSULIN HYPOGLYCAEMIA}

All the patients developed hunger, sweating, and a tachycardia after insulin and some also had feelings of tiredness, drowsiness, and palpitations. The

Table 3 Blood glucose and plasma insulin and pancreatic glucagon (mean $\doteq S E M)$ after intravenous D-glucose $(0 \cdot 15 \mathrm{~g} / \mathrm{kg}$ body weight $)$

\begin{tabular}{|c|c|c|c|c|c|c|}
\hline \multirow{2}{*}{$\begin{array}{l}\text { Time } \\
(\text { min) }\end{array}$} & \multicolumn{2}{|c|}{ Glucose $(\mathrm{mmol} / \mathrm{l})$} & \multicolumn{2}{|c|}{ Insulin (pmol/l) } & \multicolumn{2}{|c|}{ Pancreatic glucagon (pmol/l) } \\
\hline & Controls & Chagas's & Controls & Chagas's & Controls & Chagas's \\
\hline $\begin{array}{l}0 \\
3 \\
5 \\
10 \\
20 \\
30 \\
60 \\
90\end{array}$ & $\begin{array}{l}3 \cdot 8 \pm 0 \cdot 2 \\
7 \cdot 6 \pm 0 \cdot 2 \\
7 \cdot 6 \pm 0.4 \\
7 \cdot 1 \pm 0.4 \\
5 \cdot 4 \pm 0 \cdot 4 \\
4 \cdot 4 \pm 0 \cdot 5 \\
3.9 \pm 0 \cdot 3 \\
3 \cdot 6 \pm 0.3\end{array}$ & $\begin{array}{l}4 \cdot 3 \pm 0 \cdot 3 \\
6 \cdot 9 \pm 0 \cdot 5 \\
7 \cdot 1 \pm 0 \cdot 3 \\
6 \cdot 3 \pm 0 \cdot 5 \\
5 \cdot 9 \pm 0 \cdot 3 \\
5 \cdot 2 \pm 0 \cdot 4 \\
4 \cdot 2 \pm 0 \cdot 3 \\
4 \cdot 5 \pm 0 \cdot 4\end{array}$ & $\begin{array}{c}32 \pm 5 \\
166 \pm 31 \\
250 \pm 67 \\
145 \pm 25 \\
107 \pm 27 \\
52 \pm 18 \\
25 \pm 9 \\
25 \pm 10\end{array}$ & $\begin{array}{c}20 \pm 4 \\
115 \pm 52 \\
142 \pm 32 \\
82 \pm 17 \\
60 \pm 23 \\
30 \pm 9 \\
22 \pm 6 \\
21 \pm 5\end{array}$ & $\begin{array}{l}4 \cdot 5 \pm 1 \cdot 1 \\
4 \cdot 5 \pm 1 \cdot 3 \\
4 \cdot 7 \pm 1 \cdot 4 \\
5 \cdot 0 \pm 1 \cdot 5 \\
3 \cdot 5 \pm 0 \cdot 8 \\
3 \cdot 3 \pm 0 \cdot 6 \\
3 \cdot 5 \pm 0.8 \\
4 \cdot 8 \pm 0.8\end{array}$ & $\begin{array}{l}6.1 \pm 1 \cdot 5 \\
3.9 \pm 0.8 \\
3 \cdot 8 \pm 0.7 \\
3.4 \pm 0.5 \\
3.9 \pm 1 \cdot 3 \\
3.7 \pm 0.9 \\
4.3 \pm 0.7 \\
5.6 \pm 1 \cdot 1\end{array}$ \\
\hline
\end{tabular}


Table 4 Blood glucose and plasma pancreatic polypeptide and pancreatic glucagon after intravenous soluble insulin (0.15 U/kg body weight) at time 90 (mean \pm SEM)

\begin{tabular}{|c|c|c|c|c|c|c|}
\hline \multirow{2}{*}{$\begin{array}{l}\text { Time } \\
\text { (min) }\end{array}$} & \multicolumn{2}{|c|}{ Glucose (mmol/l) } & \multicolumn{2}{|c|}{ Pancreatic glucagon (pmol/l) } & \multicolumn{2}{|c|}{ Pancreatic polypeptide (pmol/l) } \\
\hline & Controls & Chagas's & Controls & Chagas's & Controls & Chagas's \\
\hline $\begin{array}{l}90 \\
120 \\
135 \\
150 \\
180 \\
210 \\
\text { Maximum value } \\
\text { achieved (minimun } \\
\text { for glucose) }\end{array}$ & $\begin{array}{l}3.6 \pm 0.3 \\
1.6 \pm 0.4 \\
1 \cdot 6 \pm 0.4 \\
1.9 \pm 0.5 \\
2 \cdot 0 \pm 0.6 \\
2 \cdot 8 \pm 0.6 \\
1.0 \pm 0.2 \\
m\end{array}$ & $\begin{array}{l}4.5 \pm 0.4 \\
1.8 \pm 0.3 \\
1.6 \pm 0.2 \\
1.8 \pm 0.3 \\
1.8 \pm 0.3 \\
2.3 \pm 0.4 \\
1.2 \pm 0.2\end{array}$ & $\begin{array}{r}4.8 \pm 0.8 \\
8.8 \pm 2 \cdot 6 \\
13 \cdot 0 \pm 4 \cdot 5 \\
15 \cdot 2 \pm 3 \cdot 8 \\
16 \cdot 3 \pm 4 \cdot 7 \\
11 \cdot 7 \pm 1 \cdot 8 \\
19.6 \pm 3 \cdot 8\end{array}$ & $\begin{array}{l}5 \cdot 6 \pm 1 \cdot 1 \\
5 \cdot 7 \pm 1 \cdot 5 \\
8 \cdot 2 \pm 2 \cdot 1 \\
9 \cdot 1 \pm 1 \cdot 6 \\
6 \cdot 6 \pm 1 \cdot 7 \\
6 \cdot 6 \pm 0 \cdot 7 \\
9 \cdot 9 \pm 1 \cdot 4\end{array}$ & $\begin{aligned} 38 & \pm 6 \\
166 & \pm 76 \\
393 & \pm 98 \\
461 & \pm 119 \\
462 & \pm 166 \\
242 & \pm 63 \\
631 & \pm 152\end{aligned}$ & $\begin{aligned} 77 & \pm 24 \\
64 & \pm 23 \\
294 & \pm 176 \\
250 & \pm 86 \\
359 & \pm 153 \\
297 & \pm 107 \\
404 & \pm 169\end{aligned}$ \\
\hline
\end{tabular}

symptoms were maximal $45-60$ minutes after the injection and were of similar severity in the two groups.

The response to insulin of blood glucose and plasma pancreatic glucagon and pancreatic polypeptide is shown in Table 4. The mean initial rate of fall was more rapid and the recovery of blood glucose was reduced in the patients with Chagas's disease but the differences were not significant. The pancreatic glucagon response was reduced in the chagasic patients, particularly at $\mathbf{2 1 0}$ minutes $(P<0.02)$ and at the maximal value achieved after insulin $(P<0.05)$. As the basal concentrations of pancreatic glucagon and pancreatic polypeptide were higher in the chagasic patients, the results were also expressed as percentage rise above basal. The percentage rise of pancreatic glucagon above basal is shown in the Figure and the difference between Chagas's disease patients and controls was significant at 180 minutes $(\mathrm{P}<0.01), 210$ minutes $(\mathrm{P}<0.05)$, and at the mean individual peak response

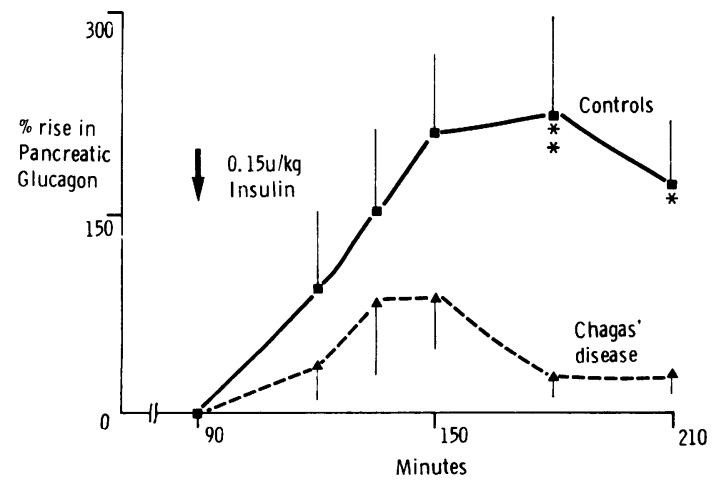

Figure Percentage rises above basal in plasma pancreatic glucagon after intravenous soluble insulin $(0 \cdot 15 \mathrm{U} / \mathrm{kg})$ in controls and patients with Chagas's disease. Vertical bars-SEM; ${ }^{*} \mathrm{P}<0.05:{ }^{* *} \mathrm{P}<0.01$. achieved $(308 \pm 38 \%$ vs $125 \pm 46 \%, \mathrm{P}<0.01)$. The percentage rise in pancreatic polypeptide was significantly lower at 120 and 135 minutes $(\mathrm{P}<0.05)$ and at 150 minutes $(\mathrm{P}<0.01)$ and at the maximal rise reached $(1541 \pm 281 \%$ vs $412 \pm 186 \%, \mathrm{P}<0.01)$.

The rise in plasma gastrin was slightly greater in the chagasic patients but this did not reach significance-for example, values at 180 minutes, $14 \cdot 8 \pm 3 \cdot 3 \mathrm{pmol} / 1$ in controls, and $23 \cdot 6 \pm 4 \cdot 0 \mathrm{pmol} / 1$ in the chagasic patients. As expected, plasma motilin fell and plasma growth hormone rose with insulin hypoglycaemia but there was no statistical significance between the two groups. Plasma gastric inhibitory polypeptide and enteroglucagon did not change from basal concentrations.

\section{Discussion}

During insulin hypoglycaemia patients with Chagas's disease have a reduced response of plasma pancreatic glucagon and pancreatic polypeptide. In view of the findings in experimental animals and vagotomised patients these results would be consistent with denervation of the alpha and PP cells in patients with chronic gastrointestinal Chagas's disease. Similar results have also been observed by us in patients with the Shy-Drager syndrome where chronic autonomic neuropathy due to degeneration of the dorsal vagal nuclei and the intermediolateral spinal column occurs. Chagasic involvement in the gastrointestinal tract has been shown to involve the local ganglia. It therefore appears that functional denervation of pancreatic hormone cells may occur from both peripheral intrinsic and central extrinsic autonomic nerve lesions.

In the presence of a decreased response of pancreatic glucagon to insulin hypoglycaemia, an increased sensitivity to and a slow recovery of blood glucose from insulin might be expected. In the insulin hypoglycaemia test the rate of fall of blood 
glucose was more rapid and the recovery slower in the chagasic patients but the differences were not significant.

The patients with chronic gastrointestinal Chagas's disease have a reduced response of plasma insulin to oral glucose in spite of initially higher blood glucose concentrations. This reduction was not associated with an impaired absorption of glucose or rise in plasma gastric inhibitory polypeptide and, consequently, these results would not appear to be attributable to reduced oesophageal or gastric emptying. After 60 minutes the blood glucose concentrations became lower in the chagasic patients than in the controls and it may be that the response in the Chagas's disease patients is appropriate to an increased insulin sensitivity.

It is recognised that in patients after vagotomy gastrin concentrations are raised and hypochlorhydria, probably due to gastric denervation, has been demonstrated in patients with Chagas's disease. ${ }^{21}$ Gastric acid secretion was not assessed in this study. The slight increase in the plasma gastrin concentrations of the chagasic patients in this study is compatible with some of the patients having either reduced gastric acid secretion and/or gastric denervation.

Motilin is known to initiate interdigestive myoelectric complexes ${ }^{22}$ and to accelerate gastric emptying. ${ }^{23}$ Abnormalities of this peptide might have been expected in symptomatic gastrointestinal Chagas's disease but were not found. Similarly, plasma enteroglucagon concentrations may be raised in patients with gastrointestinal disease ${ }^{24}$ but in the absence of a maximal stimulus - for example, a protein meal-no overall abnormality was observed.

Study of these patients thus gives additional insight into the role of innervation of pancreatic endocrine cells. It consequently appears that in patients with chronic Chagas's disease there is a functional denervation of the islet cells. Additional studies are in progress to study pancreatic exocrine function, as reduced pancreatic enzyme secretion due to denervation would be a potentially treatable explanation for the severe malabsorption and malnutrition which these patients sometimes develop.

We are very grateful to the Wellcome Trust and British Council for financial support. Doctors Long and Barnes were in receipt of Medical Research Council Training Fellowships. Professor FF Ginani kindly helped in the selection of patients.

\section{References}

${ }^{1}$ Martins Campos VJ, Tafuri WL. Chagas' enteropathy. Gut 1973;14:910-9.
${ }^{2}$ Bettarello A, Pinotti HW. Oesophageal involvement in Chagas' disease. Clin Gastroenterol 1976; 5: 103-17.

${ }^{3}$ Da Silveira GM. Chagas' disease of the colon. Br J Surg 1976; 63: 831-5.

${ }^{4}$ Bloom SR, Edwards AV, Vaughan NJA. The role of the autonomic innervation in the control of glucagon release during hypoglycaemia in the calf. $J$ Physiol 1974; 236: 611-23.

${ }^{5}$ Bloom SR, Edwards AV, Hardy RN. The role of the autonomic nervous system in the control of glucagon, insulin and pancreatic polypeptide release from the pancreas. J Physiol 1978; 280: 9-23.

${ }^{6}$ Russell RCG, Thompson JPS, Bloom SR. The effect of truncal and selective vagotomy on the release of pancreatic glucagon, insulin and enteroglucagon. Br J Surg 1974; 61 : 821-4.

${ }^{7}$ Feldman M, Richardson CT, Taylor IL, Walsh JH. Effect of atropine on vagal release of gastrin and pancreatic polypeptide. J Clin Invest 1979; 63: 294-8.

${ }^{8}$ Pedreira de Freitas JL, Mendonça W. Inquérito sobre moléstia de Chagas no municipio do Rio Verde (Estado de Goias). Hospital (Rio de Janeiro) 1951 ; 39: 251-61.

${ }^{9}$ Teixeira ARL, Teixeira G, Macêdo V, Prata A. Acquired cell-mediated immunodepression in acute Chagas' disease. J Clin Invest 1978; 62: 1132-41.

${ }^{10}$ Albano JDM, Ekins RP, Maritz G, Turner RC. A sensitive precise radioimmunoassay of serum insulin relying on charcoal separation of bound and free hormone moieties. Acta Endocrinol 1972; 70 : 487-509.

${ }^{11 B j o ̈ r n s s o n ~ O G, ~ A d r i a n ~ T E, ~ D a w s o n ~ J, ~ e t ~ a l . ~ E f f e c t s ~ o f ~}$ gastrointestinal hormones on fasting gallbladder storage patterns in man. Eur $J$ Clin Invest 1979; 9: 293-300.

${ }^{12}$ Bloom SR, Mitznegg P, Bryant MG. Measurement of human plasma motilin. Scand J Gastroenterol 1976: 11 suppl 39: 47-52.

${ }^{13} \mathrm{Jacobs}$ HS. Use of activated charcoal in the radioimmunoassay of human growth hormone in plasma. J Clin Pathol 1969; 22 : 710-7.

${ }^{14}$ Russell RCG, Bloom SR, Fielding LP, Bryant MG. Current problems in the measurement of gastrin release. A reproducible measure of physiological gastrin release. Postgrad Med J 1976; 52: 645-50.

${ }^{15}$ Sarson DL, Bryant MG, Bloom SR. A radioimmunoassay of gastric inhibitory polypeptide in human plasma. J Endocrinol 1980; 85: 487-496.

${ }^{16}$ Alford FB, Bloom SR, Nabarro JDN. Glucagon levels in normal and diabetic subjects: use of a specific immunoabsorbent for glucagon radioimmunoassay. Diabetologia 1977; 13: 1-6.

${ }^{17}$ Barnes AJ, Bloom SR. Pancreatectomised man: a model for diabetes without glucagon. Lancet 1976; 1:219-21.

${ }^{18}$ Barnes AJ, Bloom SR, Alberti KGMM, Smythe P, Alford FP, Chisholm DJ. Ketoacidosis in pancreatectomized man. N Engl J Med 1977; 296: 1250-3.

${ }^{19}$ Thompson JPS, Bloom SR. Plasma enteroglucagon and plasma volume change after gastric surgery. Clin Sci Mol Med 1976; 51 : 177-83.

${ }^{20}$ Jorgensen KR, Larsen UD. Purification of ${ }^{125}$ I glucagon by anion exchange chromatography. Horm Metabolic Res 1972; 4: 223-4. 
${ }^{21}$ Padovan W, Meneghelli UG, de Godoy RA. Gastric secretory and motility studies in chronic chagasic patients. Am J Dig Dis 1977; 22: 618-22.

${ }^{22}$ Vantrappen G, Janssens J, Peeters TL, Bloom SR, Christofides ND, Hellemans J. Motilin and the interdigestive migrating motor complex in man. Dig Dis Sci 1979; 24: 497-500.
${ }^{23}$ Christofides ND, Modlin IM, Fitzpatrick ML, Bloom SR. Effect of motilin on the rate of gastric emptying and gut hormone release during breakfast. Gastroenterology 1979; 76: 903-7.

${ }^{24}$ Besterman HS, Bloom SR, Sarson DL, et al. Guthormone profile in coeliac disease. Lancet 1978; 1: 785-8. 